\title{
A propòsit de la "cultura" en les festes de Borriana. Cinc dates significatives
}

\author{
JoAn EMili Gumbau GonzÁLez (juane.gumbau @salesianos.edu) \\ Col·legi Salesià Sant Joan Baptista de Borriana
}

\section{Consideracions prèvies}

Abans d'iniciar aquest article i, per a evitar interpretacions errònies, és convenient fer un aclariment al voltant de la paraula cultura.

La definició acadèmica ens diu que cultura és la unió de les conductes i comportaments d'una comunitat. Aquesta idea, però, se'ns queda curta, ja que les actituds, els valors, els objectius i les pràctiques d'aquest conjunt d'éssers amb visió més o menys semblant d'un temps i unes circumstàncies també haurien d'entrar en la susdita definició. És més, no podem ignorar que cultura seria també el llegat que una comunitat fa a les generacions futures.

Alejandro Espinosa-Patrón (2010) ens recorda que, en 1982, la Unesco recomanà que la cultura s'entenga com el conjunt dels trets distintius espirituals, materials, intellectuals i afectius que caracteritzen una societat o grup, i que abasta, a més de les arts i les lletres, el mode de vida, la convivència, el sistema de valors, les tradicions i les creences.

De les consideracions anteriors es collegeix que la cultura d'un poble - en el sentit de comunitat - abasta àmbits tan diversos com ara la literatura, la gastronomia, la vestimenta, la música, la cançó, els ritus, els codis, els comportaments, les creences i altres molts més aspectes.

El títol, per tant, d'aquest article, suggereix un amplíssim ventall de possibilitats, inversament proporcional, per força, a la seua extensió. Paga la pena, doncs, acotar l'objectiu que persegueix per a no crear falses expectatives. D'aquesta manera, l'article pretén ser una visió general de la cultura que subjau en les festes més significatives que se celebren a Borriana en l'actualitat. Concretament en parlarem de cinc: Sant Blai, les Falles, la Misericòrdia, la Mercè i l'Ecce Homo.

Abans, però, de fer una ullada a aquestes festes, caldria, si més no, fer palès un segon aclariment. Com la majoria dels pobles, gran part de la cultura de Borriana és hereva de la cultura religiosa popular. Antoni Ariño ho assenyala ben bé en els primers compassos del seu llibre Festes, rituals $i$ creences (1988), on insisteix en la importància que té la religió - en el seu vessant més popular- en els elements festius actuals. El mateix Ariño aporta una nova font de l'entramat festiu de les nostres terres: el camp. Efectivament, si observem el calendari festiu de Borriana, podrem trobar innumerables influències d'aquests dos paràmetres: la religió popular i el món de l'agricultura. El segon element és, evidentment, un signe inequívoc del passat de la nostra "ciutat".

Un element imprescindible en les festes religioses és la processó, on el fervor de la feligresia es fa palès en un ritu tan antic com consagrat. En cada manifestació processional la posició de cada personatge és de vital rellevància i ens recorda el paper dels poders religiosos i polítics en els pobles. 
Concretament a Borriana, el fet processional no es redueix al patronatge de sant Blai -3 de febrer - o de la Mare de Déu de la Misericòrdia - 8 de setembre - , sinó que es trasllada a cada parròquia, fins i tot a les ermites, com ara l'Ecce Homo. Aquesta devoció cristològica i mariana està plena de ritus, de reminiscències del passat, de cultura popular en definitiva.

Un altre aspecte religiós impregnat de cultura és la gogística. Com assenyala Josep Palomero en l'article que dedica a la literatura popular de Borriana en el segon volum de Burriana en su història, la tradició gogística a la nostra ciutat ve d'antic i es conserva ferma. Palomero destria els gojos propis de Borriana i els gojos que compartim amb altres poblacions. Tenim, doncs, gojos per a la Mare de Déu de la Misericòrdia, sant Blai, santa Bàrbara, l'Ecce Homo i la Sagrada Família de les Alqueries del Ferrer.

Quant a l'aspecte festiu, caldria fer també un breu apunt. Deia Roman Jackobson que l'home és un ésser social, amb una imperiosa necessitat de relacionar-se. I la festa es pot entendre com un perllongament d'aquesta necessitat. Ana Zabalza Seguín (2007) parla de la festa com un ritu que indica pas i commemoració. La festa es converteix en una clara mostra de la identitat d'un poble, i acompleix, doncs, una funció social. Les festes patronals són molt il-lustratives en aquest sentit, ja que en aquestes el poble viu agermanat de manera especial, amb intensa vivència de la festa que mostra en diferents actes, processons, desmesures... I a tall d'exemple: els porrats que se celebraven - ara ja en són pocs - el dia del sant del carrer aglutinaven - o aglutinen - els veïns al voltant d'activitats gastronòmiques, jocs per als menuts, joneguets... Tot açò, per descomptat, fomentava l'entramat associatiu del poble. En alguns d'aquests porrats se sortejava la capelleta — capsa de fusta amb la imatge del sant - per a veure quina casa li donava aixopluc durant un any, de vegades amb el compromís de fer una festa en el seu honor.

Per a acabar aquestes consideracions prèvies, farem un breu apunt sobre la tensió que existeix entre el canvi i la continuïtat en la cultura d'un poble. Per a fer-se'n una idea sols cal observar com, en cada festa, hi ha un component del passat d'aqueix poble que roman, mentre se n'afegeixen de nous, els quals donen a la festa una fesomia pròpia. És, si més no, com inserir el passat en el present. Veure una cercavila, amb el cerimonial i l'ordre que suposa, és contemplar el passat, rememorar-lo amb la flaire dels nous temps. Evidentment, unes festes respecten més la tradició que unes altres, però en totes trobem una barreja de canvi i continuïtat.

Fetes les consideracions prèvies, passarem ara al cas concret que ens ocupa, les festes de Borriana. No cal incidir en el fet que, per motius d'extensió, algunes festes - que ningú no se senta ofès - no es reflectiran en aquest article, supressió que, de cap manera suposa oblit. Així doncs, ens centrarem, tot i que sumàriament, en cinc fites al calendari festiu borrianenc, amb els actes que duen aparellades i l'entreteixit cultural.

\section{Festes}

\subsection{Sant Blai, 3 de febrer}

Als pobles, com és el nostre cas, de tradició rural, la festa del patró té un caire especial. Antigament, tant el consistori com la gent del carrer concentraven esforços i recursos per a la festa gran del poble. Així doncs, les activitats se succeïen i eren 
aplaudides i concelebrades per la majoria dels veïns i visitants. A Borriana, els dos patrons, sant Blai i la Mare de Déu de la Misericòrdia, tenen festa pròpia, cadascuna preparada i viscuda de manera diferent. Roca i Alcaide, en la seua Historia de Burriana, dedica el capítol XLVIII a les festes del poble. La primera que l'historiador ressenya és la de sant Blai. Llegint-lo, hom pot adonar-se que la festa del patró no ha canviat en essència (Roca i Alcaide, 1932: 343).

Empiezan los festejos de San Blas el día 2 de febrero, con el obligado vuelo de campanas, inauguración de la feria i conducción de la imagen del Santo desde el ermitorio en que se venera el antiguo cuadro [...] a la Iglesia Parroquial.

En la mateixa pàgina, un poc més endavant, dirà:

El día 3 de febrero, comienza con vuelo general de campanas, disparo de morteretes y diana por las bandas de música. [...] Un festejo originalísimo se celebra a las seis de la mañana de este día 3; la Font del Vi, instituida de antiguo para obsequiar a los forasteros y vecinos que acuden a venerar al Santo. Costumbre en la época en que abundaban las viñas del campo.

Després, ens relata l'historiador, se celebrava la missa major i en els dies següents - excloent-hi el dia 4, dedicat als difunts del darrer any- es duien a terme diferents festejos, entre els quals destacava la cursa de cavalls al camí de la Cossa.

Si comparem la narració dels anys trenta amb la festa actual del patró a Borriana, no observem, en realitat, grans variacions. Desistim d'anar més enrere de l'estudi de Roca i Alcaide, ja que no ens interessa tant la història, com la consolidació d'unes tradicions al voltant de la festa patronal. En el programa de 2013 es pot comprovar que la base religiosa - amb la novena, la vigília al patró i la missa del dia gran - es manté. També perviu l'activitat més emblemàtica del dia 3 de febrer, la Font del Vi, que fou instaurada en 1854 (Verdegal, Olivares, 2004: 30). En aquesta s'hi veu reflectida la tradició vitivinícola de la població, assenyalada per Roca i Alcaide, però el que ens importa és com, desapareguda aquesta activitat al voltant del raïm, continua celebrant-se aquest curiós esdeveniment que consisteix en una mena de font amb diverses aixetes a les quals es connecten mànigues que subministren el vi. Hui en dia la primera ubicació, davant de l'Hospital, desaparegut aquest, ha deixat de tenir sentit, així que se situa al final del carrer de Sant Blai. L'Hospital, i el cementeri adjacent, eren construccions annexes al temple de Sant Blai, que fou reconstruït en 1882 (Verdegal, Olivares, 2004: 34). També l'hora ha variat; des de fa uns anys s'ha endarrerit l'esdeveniment. Temps enrere es va instaurar la declamació de poemes, prèviament a la inauguració de la Font, sobretot dels que Juan Bautista Tejedo Beltrán, el Bessó, dedicà a sant Blai. Observem com, de nou, la literatura popular se'n fa ressò en les festes i és valorada i esperada pels veïns assistents.

\subsection{Les falles, motor de festa i tradició}

Si hi ha unes festes que duen aparellada la tradició — i per tant la cultura -, aquestes són les falles. És evident que les festes josefines a la nostra localitat gaudeixen d'una 
vitalitat envejable. Tant és així que en els darrers anys han augmentat les comissions fins a un total de dènou, amb la nova incorporació de la Falla Societat Cardenal Tarancon. La colllaboració de les comissions falleres en la cultura abasta un ventall d'àmbits com la indumentària tradicional, el teatre, la poesia, la literatura satírica i d'investigació en els llibrets de falla, les creus de maig, el mateix monument $i$ altres actes $i$ tradicions que tenen existència pròpia gràcies al món faller. Cadascun d'aquests mereixeria un capítol a banda, cosa que, com hem exposat al principi de l'article, no es produirà. Quedaran fora, per tant, activitats tan interessants com la música fallera, la poesia satírica i de lloança, les creus de maig, per cert, exhaustivament estudiades en l'il·lustrador treball de Julián Arribas Les creus de maig. Dedicarem, això sí, un espai a dos aspectes: el teatre i els llibrets de falla.

José Aymerich Tormo, en Burriana, en sus fallas, volum I, rememorava l'aparició de la primera falla, la de la plaça del Convent — actual Mercè- i, amb aquesta, la del primer llibret-explicació, del mestre Pedro Ferrer, qui satiritzava el comerç de la taronja d'aqueix temps. Recordats són els versos que encapçalaren la crítica de la falla «En la Plaça del Convent/ ja tots la notícia saben/ i de dir-ho no s'amaguen/ què parlaora és la gent [...]». S'encetava així un prolífic camí per a la literatura satírica popular del segle XX a la nostra ciutat, hereva, sense dubte, de la tradició satírica del segle XV i el caràcter jocós del valencià. Cal destacar l'aportació al susdit tema del llibret de La Vila de l'any 2012, amb el magnífic monogràfic que Julián Arribas i Toni Gil dedicaren als llibrets de falla. D'aleshores ençà, molts han estat els afeccionats i lletraferits que han dedicat part del seu art a la poesia satírica popular dels llibrets de falla, sense oblidar, és clar, la poesia de lloança a les falleres. Aquells Pere Echevarría, Manuel Peris Fuentes, Juan Bautista Tejedo Beltrán el Bessó, Bernat Artola, José Aymerich Tormo, Roberto Roselló i tants altres, van sembrar la llavor continuada per autors contemporanis. Potser hui en dia s'atribueix l'autoria dels llibrets a les falles com a associacions, i es deixa en segon pla els crítics i autors d'exquisides i valuosíssimes monografies sobre qüestions diverses de la nostra tradició i cultura valenciana i borrianenca. Potser siga perquè la majoria forma part de la comissió, però la labor que han dut a terme és impagable. Quasi tots destacables, cal assenyalar brillants estudis d'investigació o, simplement, compilació, que s'han dut a terme en les dues últimes dècades. Els llibrets de falla es converteixen, així, en els documents de difusió més efectius de la cultura popular de la nostra ciutat. D’aquesta manera, els llibrets ens parlen d'indumentària tradicional i fallera, de mantenidors i literatura, de gastronomia, de tapissos, dels cartells de falles, de pintes i adreços, de l'art de construir i pintar els monuments fallers, de jocs populars, del nostre mercat, de la Panderola, de cançons populars, de costums del poble, de protocol faller, de teatre en valencià, de les creus de maig, dels mantenidors, de personatges lligats a les falles: Pepet, Regino, Dualde, etc. De tants i tants temes que la llista, per inacabable, és inapropiada en aquest article.

L'altre punt de l'activitat fallera que destaquem per l'aportació que fa a la cultura és el teatre.

El teatre, i en especial les peces còmiques, han gaudit d'un gran arrelament en la cultura valenciana. Potser el caràcter llevantí facilita un espectacle on la sàtira i l'humor són els ingredients principals. Al voltant del tema, Carme Rufino, en el llibret de la Falla Plaça Chicharro, de 2010, dedica un monogràfic molt il·lustrador. I és ara quan, tot i desviarnos de l'itinerari d'aquest treball, ens permetrem la llicència de recuperar certa informació 
del passat. Efectivament, com Rufino assenyala, els primers sainets - obres dramàtiques de curta durada i caràcter humorístic - giren al voltant de l'enfrontament entre l'ambient rural de València i els urbanites, i prenen com a motiu de conflicte l'abandó del valencià per les classes més pròsperes. Josep Bernat i Baldoví i Eduard Escalante potser siguen els noms més coneguts i reconeguts pel públic d'ara i d'adés. L'èxit del sainet a València ve, segurament, determinat per la representació continuada d'obres de més envergadura, ja que servien de complement per a aquestes. Prompte comencen a haver-hi companyies estables i representacions contínues. Estava clar que l'èxit assolit al Cap i casal havia d'arribar a la ciutat de Borriana, que tantes coses imitava de la capital. El treball de Rufino parla del primer teatre documentat a Borriana, l'1 de juny de 1877. Estava enclavat a la part sud de l'exconvent de la Mercè, després vingueren altres teatres, com el de la Vila, cedit a J. V. Sabater, qui departia els beneficis amb l'Hospital. Aquesta pràctica no era nova, ja que, al segle XVI, era habitual en molts teatres, corrals o coliseus de les ciutats importants. De fet, en alguns es pagaven dues entrades, una per a l'empresari i una altra per a l'hospital o confraria. A Borriana, la moda teatral seguia en voga. El mateix Sabater n'obrí un, de nou, a la vora del campanar; un altre aparegué al carrer de Rochera — actualment la UGT_, anomenat Vico, i també altres salonets provisionals. I ni les grans sales, com ara el primerenc Circ Teatre Oberon, pogueren tallar la necessitat popular de fer el seu teatre. Apareixen així companyies d'afeccionats, com la Societat Filharmònica Borrianenca, Viciana o el teatre de la UGT, on actuava el més que conegut Baoro. També La Grillera desenvolupà una tasca ingent en l'apartat teatral i de la cultura en general. La guerra civil anul-là pràcticament el sainet, sobretot en valencià. Amb el pas dels anys, el teatre de gran format reviscolà, però no així el sainet, al qual li arribà el declivi. Les sales de cine s'omplien, mentre que el sainet estava ferit de mort. Únicament representacions esporàdiques mantingueren la flama del sainet viva. Als anys huitanta algunes comissions falleres reprengueren més animosament la representació de sainets, però no suposà una continuïtat destacable. Haurem d'esperar al nou mil·lenni per a veure una tendència teatral ferma i amb garanties d'aqueixa anhelada continuïtat.

Així, l'any 2006 la Falla la Ravalera i la Societat Centre Espanya iniciaren de nou aquesta activitat teatral de les comissions falleres. Feia dues dècades que no es representaven pràcticament obres teatrals a les falles. Les noves obres eren Vicenteta, este any sóc president, de José Vicente Tormos Arnandis, i Ser polític me va, de Paco Ferrer Fonseca. El motiu de la iniciativa era, evidentment, econòmic, una altra manera de recaptar diners - cosa en què les comissions falleres són autèntiques expertes. L'exercici següent (2006-07) començava el concurs de teatre en valencià, adreçat a les comissions falleres. De nou repetien les dues mateixes falles. El tercer any en foren tres, els sainets. Perquè, pròpiament, les obres a concurs eren, primerament, sainets, tot i que el títol del concurs parlava de teatre en valencià. En realitat, la tònica del concurs aquests anys ha estat l'obra còmica, a l'estil dels sainets, tot i que algunes comissions hi han incorporat elements teatrals més acords amb les estètiques modernes, com l'expressió corporal, el so, els efectes de llum, decorats minimalistes... Durant l'exercici 2008-09, en foren set, i l'any 2011, s'arribà a dotze obres presentades. Fins al cinquè any — quart del concurs-, les representacions es feien al teatre Payà però, amb motiu de la remodelació del local, l'espai que oferí l'Ajuntament fou la Casa de la Cultura. L'exercici 2013-14 ha ofert la possibilitat de tornar al teatre Payà per a dur a terme les representacions de les diferents comissions. Quant als autors de les 
obres, cal assenyalar que cada vegada són més els autors borrianencs que es decideixen a escriure'n una. El premi d'obra inèdita premia la tasca d'aquells escriptors que atorguen una nova peça a les comissions. De tota manera, el reconeixement és únicament una de les motivacions, perquè no són poques les comissions que han descobert en aquesta activitat una autèntica realització personal, a més d'una companyonia envejable. Amb consciència o no, les falles són, a hores d'ara, les associacions més actives en l'apartat teatral. De les falles han sorgit grups de teatre com Bambolina Teatre, de la Falla Sant Josep, o 5tres, de la Falla Societat Club 53. I cal no oblidar la incursió que algunes falles han fet en el musical, tan de moda en l'actualitat. En definitiva, queda clarament justificat que el món de la falla aporta considerables aportacions al teixit cultural borrianenc.

\subsection{La Misericòrdia, 8 de setembre}

La festa de la patrona se celebra a Borriana amb una intensitat especial. De fet, podem dir que és la més multitudinària de les festes populars. Durant el mes d'agost es fan els preparatius per a una festa que té lloc durant més d'una setmana i on l'element taurí és el motiu central. Gent d'edats molt diverses — alguns comencen amb catorze anys o menysformen colles, que a Borriana anomenem "penyes", per a anar als cadafals i veure-hi el bou o simplement xarrar i menjar tramussos, cacaus, faves i altres aliments típics. Moltes "penyes" condicionen un casal — una planta baixa, garatge o semblant — on pràcticament viuen aqueixa setmana. La festa i tradició religiosa queda quasi reduïda al dia de la patrona, el 8 de setembre, en el qual es duen a terme els actes típics com ara missa, processó, etc. Des de fa uns anys s'ha recuperat una activitat que es feia antigament a la nostra terra, els fanalets. Els xiquets buiden un meló — normalment d'Alger - i tallen figures - estrelles, llunes, lletres, etc. - en la corfa. Dins del meló es col·loca un ciri i es lliguen unes cordes de la part superior per a poder transportar-lo. En acabat, tots els xiquets i xiquetes fan una processó nocturna lluint els fanalets encesos al públic assistent. La festa acaba el diumenge després de la Misericòrdia, amb la tradicional batalla de flors, en la qual les falles llueixen carrosses fetes de paperets des de les quals les falleres i fallerets llancen confeti multicolor. Aquestes carrosses, que suposen el colofó de les festes de la Misericòrdia, foren instaurades en el govern de Joaquín Urios (Arribas, 2011: 128) per a substituir els bous al carrer. Així, el 7 de setembre de 1958, a les sis de la vesprada, desfilaren per Borriana catorze carrosses, a imatge del Cap i casal, on ja es realitzava.

Com a comentari, cal dir que es pot estar d'acord o no amb la festa dels bous, però és innegable el poder de convocatòria que té, no sols al nostre poble, sinó també als de la rodalia. Perquè, no únicament es fan bous a la Misericòrdia, sinó durant altres festes del poble com ara al barri de l'Ecce Homo, els dels Desemparats o les festes de la Mare de Déu del Carme, al port. Antigament, fins i tot se'n feien durant les festes del patró (Verdegal, Olivares, 2004: 30).

\subsection{La Mercè, 24 de setembre}

Una de les festes de la nostra localitat que crida l'atenció per la vigoria que demostra hui en dia és la de la Mercè. Potser siga perquè als integrants de la Confraria de la Mare de Déu de la Mercè se'ls hi afegeix la resta de la parròquia, la falla que du el mateix nom, 
la recentment creada Associació de Gegants i Cabuts de Borriana i els feligresos i veïns del barri, incondicionals d'aquesta festa. La suma dels factors humans esmentats fa que l'església en què ha derivat la primitiva ermita de Sant Mateu, habilitada i ampliada com a convent mercedari (Gil, 1991: 247-250), gaudisca d'una envejable salut. En la festa de la Mercè es barregen els elements religiosos amb uns personatges molt peculiars que sorprenen la gent de Borriana i els de fora: els gegants i els cabuts. El Diccionari CatalàValencià-Balear d'Alcover i Moll defineix gegant com «cadascuna de les figures d'home o dona de gran estatura que són portades en certes processons i festes populars» i nano - que prenem com a sinònim de cabut, cabet o capgròs - com «cadascun dels homes o nois que, amb els caps ficats dins grans caps grotescs de cartó que els donen aspecte de curts de cos, assisteixen a la processó del Corpus i a altres festes populars ballant i fent evolucions per a diversió de la gent». A València, la primera notícia de la desfilada de gegants i cabuts en la processó del Corpus sembla que és de 1588, en una carta dels jurats de València a un síndic que es troba a Madrid. Sí que pareix segur que en 1599 participaren en alguns actes durant la visita que Felip V féu a València amb motiu del casament del fill. A Borriana, haurem d'esperar fins al segle xx i no precisament en la festa del Corpus.

La festa de la Mercè, com hui en dia la coneixem, comença la vespra, amb la processó dels gegants i els cabuts. Són aquests uns personatges que connecten amb els oriünds i sorprenen els visitants. La tradició dels gegants i cabuts és una tradició que es dóna a molts països i que ve de lluny, ja que apareix, més o menys com l'entenem, en l'edat mitjana. De tota manera, hi ha referències a aquests personatges grotescos en moltes cultures. Hui en dia té la màxima esplendor a Catalunya, on es pot veure a més d'un miler de pobles, tot i que també se celebren en uns altres llocs de la geografia espanyola i europea. En la majoria d'aquests indrets serveixen per a festejar-hi el Corpus, fet en què difereix la festa borrianenca. L'origen de l'aparició d'aquests curiosos i entranyables personatges data a Borriana dels anys vint, en què desfilaren pels carrers de la barriada de la Mercè, dos gegants i sis cabuts, segons indica el blog de l'associació esmentada. De fet, és molt possible que aqueix fóra el nombre de personatges — dos gegants i sis nans o cabuts-, no des de l'inici on hi havia dos nans, però sí des de ben prompte. Sembla que, a Borriana, fou Carles Romero, aquell sagristà que juntament amb altres persones donà inici a la festa de les falles a la nostra ciutat, amb l'ajut d'altres veïns dels quals no ens consta la identitat, qui posà en marxa la festa dels gegants i els cabuts, a imatge i semblança de València i d'algunes localitats catalanes. Des del començament s'ha seguit la mateixa dinàmica: una desfilada informal la vespra de la festa anunciant l'esdeveniment de l'endemà, i l'encapçalament de la processó del dia gran. És, aquesta, una estructura antiga, ja que els nans o cabuts sempre han encapçalat la processó perseguint els xiquets, com consta al llibre Gegants $i$ cabuts, dins de la col·lecció Tallers de Cultura Popular Valenciana, de l'Escola Valenciana. La "processó" informal amb danses i balls de la vespra s'acompanya, a la nostra ciutat, amb el so de la dolçaina i el tabal. Antigament i encara ara, a algunes localitats, es fan sonar altres instruments, com ara els sacs dels gemecs — gaites-, la gralla, les closques o altres.

Hui en dia, a Borriana, podem contemplar-hi gegants antics i nous. Els primers, Blai i Mercè - en honor als patrons de la ciutat-, són una rèplica dels que hi havia abans dels anys huitanta, que es construïren allà per l'any 1982, o potser 1983, per Juan Muñoz i Pasqual Xiva. L'any 2009, l'artesà faller Xavier Ribes, ajudat per Enrique Lloret i Vicent 
Moliner, segons fa constar al seu web l'Associació de Gegants i Cabuts de Borriana, restauraren aquests gegants antics, que s'abillaren amb roba tradicional de mudar dels valencians del segle XVIII. Els gegants nous daten de l'any 2002, obra de l'artesà faller més reconegut de Borriana, José Pascual, Pepet, i se'ls coneix amb els diminutius dels antics, Blaiet i Mercedetes, ja que en un principi havien de substituir els anteriors.

Quant als cabuts - cabets o capgrossos, aquesta darrera denominació utilitzada a Catalunya-, cal destacar que, actualment, Borriana compta amb dotze. Originalment sembla que n'eren sis, i duien una castanyola que feia les vegades d'instrument de percussió, mentre els assistents cantaven:

\footnotetext{
Xocorroc cotxera, tira'm una pera, xocorroc cotxoc, i un albercoc.
}

Finalment, l'última percussió la feien suaument sobre el cap d'algun xiquet pròxim -l'anomenat "carxot". Açò derivà en l'autèntica batalla que els cabuts i els xiquets duen a terme. Els primers persegueixen els xiquets i els peguen al cap amb la castanyola; els xiquets es defensen amb periòdics enrotllats.

És curiós com algunes tradicions arrelen en els pobles i unes altres es perden en el pou de l'oblit. Aquesta dels gegants i cabuts, a banda de la cridanera aparença dels protagonistes, compta amb la participació del públic - més concretament els xiquets-, la qual cosa la fa molt atractiva i li augura la pervivència.

Però, lògicament, en ser una festa dedicada a la Mare de Déu, els actes centrals són religiosos. Comencen, com en les festes patronals, amb la novena, els dies anteriors, i la vigília o vetlla, la vespra de la festa. Cal destacar que quan s'acaba la novena es canta l'himne que, en aquest cas, es pren del cant de la Mare de Déu de Barcelona «A Barcelona del cielo,/ la caridad os inclina...». La Confraria de la Mare de Déu de la Mercè és l'encarregada d'aquests actes. Durant anys aquesta vetlla s'ha acompanyat de música i cançons, tot i que el darrer any, a causa de la crisi, se n'ha hagut de prescindir. És costum que alguns devots oferesquen presents a la Verge com ara arracades o collars, que es posen en la imatge que l'endemà eixirà a la processó. El dia 24 de setembre se celebra la missa i la processó, encapçalada, com ja hem comentat, pels gegants i cabuts, seguits dels feligresos i la imatge de la Verge; en acabat, les clavariesses i les autoritats religioses i consistorials. Com en altres processons, la disposició dels participants té un sentit que cal respectar. Antigament, desfilaven també els xiquets del carrer, abillats com captius, i les xiquetes com a veròniques, tradició que, fins fa poc, encara es duia a terme. També cal destacar l'anomenada «Dansa dels pastorets», una de les més antigues de les nostres terres, que es ballava durant la processó. El grup de dansa l'Arenilla recuperà aquesta dansa popular l'any 2001.

\subsection{L'Ecce Homo, 12 d'octubre}

En el llibre El camí de les ermites de Burriana (2003) - la 'u' del topònim era, en aqueix temps conditio sine qua non per a fer publicacions municipals-, l'autoria del 
qual compartesc amb Hèctor Carda i Josep Nos, s'explica que a finals del segle XVIII es trobà a unes terres de la partida del Rovellat una imatge en relleu que representava Jesucrist rebutjat i condemnat per Pilat. Aqueix fou l'inici de l'ermita de l'«Axiamo» o «Acciamo» - curiosa evolució en la nostra parla local de l'expressió llatina Ecce Homo - i de la festa que en gira al voltant. Relacionades amb el culte podem trobar diverses pràctiques devotes com ara el pelegrinatge que els fidels duen a terme pel camí de l'Ecce Homo fins a l'ermita tots els divendres, que fou el dia en què es descobrí la troballa, o el costum de fer-hi una fira el dia 12 d'octubre, dia de la festa gran. Però, més curiosa és la pràctica que no pocs fidels duen a terme en l'ermita: la presentació d'exvots de cera, els quals representen la part del cos per la qual han demanat a Déu. Aquesta pràctica, que es troba també en altres pobles, omplia l'ermita de figuretes amuntegades que li conferien un aspecte tètric. Hui en dia la sala es mostra més ordenada i amb mostres testimonials d'allò que fou un dia. El recordat Juan Bautista Tejedo Beltrán en Els divendres a l'Acciamo li dedicà uns versos que acaben de manera molt il·lustradora:

[...] com no fer-te els divendres

pelegrinatge?

Quin burrianenc no estima

la teua imatge?

\section{Valoracions finals}

Se'ns han quedat marcades en el calendari diverses festes amb tradicions pròpies que, per qüestions òbvies d'espai, no abastem a comentar. La curiosa processó dels animals de sant Antoni, les processons de Setmana Santa, el passeig en vaixell dels mariners en les festes del Carme, els Desemparats, sant Nicolau, etc. Però, després d'haver donat una ullada a algunes d'aquestes, totes imbuïdes de cultura, ens preguntem per què els veïns i veïnes d'una localitat senten les festes del poble tan seues. Evidentment, perquè les viuen, perquè hi participen, les senten seues perquè en formen part. De fet, les festes no són sinó una projecció de la gent d'un poble. Amb les mateixes recordem el que vam ser, el nostre passat, i alhora els donem un caràcter propi de l'època en què vivim. Açò és, canvi i pervivència; passat i present. Ací rau l'essència de la festa. Allò que vam ser els borrianencs, perviu en la festa, en les tradicions, processons, pràctiques, ritus... i allò que som, vessa en la mateixa festa, mitjançant noves pràctiques o simplement en la participació. I tot açò ens du a una consideració amb la qual tanquem l'article (Gumbau, 2009: Pròleg):

La història quotidiana - eixa intrahistòria unamuniana-, la de la lletra minúscula, és la que conforma el caràcter d'un poble. Un caràcter que es nodreix del folklore, dels costums populars, de les festes i tradicions. I, curiosament, són aquestes coses les que fan feliç a la gent.

I no és la felicitat allò que cerca tothom? Celebrar i concelebrar, doncs, les festes i la cultura - que insufla d'autèntica vida a aqueixes - és una manera d'assolir la felicitat. 


\section{BIBLIOGRAFIA}

EsPinosa-Patrón, A. (2010): «Aproximación a una teoría de la fiesta del Rey Momo a partir de la tríada comunicación, cultura y carnaval», Palabra Clave, 13, 160-175.

ABAD, V. (2011): Borriana siglo XX, València, Tirant lo Blanch.

ARIÑo, A. (1988): Festes, rituals i creences, València, Alfons El Magnànim / Institució Valenciana d'Estudis i Investigació.

Arribas, J. (2009): Burriana en sus fallas, II, Borriana, Grup d'Estudis Històrics Fallers. - (2009): «La batalla de flors», dins de Llibret de la Falla la Vila 2009, Borriana, Falla la Vila.

Arribas, J. i A. GiL: (2012) «Llibrets de falla», dins de Llibret de la Falla la Vila 2012. Foc, pólvora $i$ art, Borriana, Falla la Vila.

Aymerich, J. (1996): Burriana en sus fallas, I, Borriana, Grup d'Estudis Històrics Fallers.

DDAA (1986): Burriana en su historia, I, Borriana, Magnífic Ajuntament de Borriana.

Gil CABrera, J.L. (1991): «El Convent Mercedari de la Mercè», dins DDAA: Historia de Burriana II, Borriana, Magnífic Ajuntament de Borriana.

Gumbau, J.E., (2009): «Pròleg», dins Arribas, J.: Burriana en sus fallas, II, Borriana, Grup d'Estudis Històrics Fallers.

Gumbau, J.E., Carda H. i J. Nos (2003): El camí de les ermites de Burriana, Borriana, Magnífic Ajuntament de Borriana.

Montoliu, J.J. (1995), La Merced y Burriana, Borriana, Parroquia Nuestra Señora de la Merced.

PAlomero, J. (1991): «La literatura popular a Borriana», dins DDAA: Historia de Burriana II, Borriana, Magnífic Ajuntament de Borriana.

Roca i Alcaide, F. (1932): Historia de Burriana, Borriana, Magnífic Ajuntament de Borriana.

Rufino, C. (2010): «L'èxit del sainet faller a Borriana», dins de Llibret de la falla plaça Chicharro 2012, Borriana, Falla plaça Chicharro.

Verdegal, J.M. i G. Olivares (2004): Iconografia devocional de Borriana. Memòries de carrer, Borriana, Magnífic Ajuntament de Borriana.

Zabalza Seguín, A. (2007): «Obligación y devoción. Fiestas patronales en Navarra en el siglo XVIII», Cuadernos de etnología y etnografía de Navarra, 82, 265-280.

$<w w w . u n e s c o . o r g>$.

$<w w w . b o r r i a n a . e s>$.

\section{BIONOTA}

\section{Joan Emili Gumbau González}

Nascut a Borriana (12 de febrer de 1970), és llicenciat en Filologia Hispànica per la Universitat de València, especialitats de Literatura Espanyola i Literatura Valenciana. Actualment treballa al Col-legi Salesià de Borriana com a professor de Llengua i Literatura en secundària i batxillerat. Compagina aquesta tasca amb l'escriptura de novel-les adreçades a joves i infants. L'any 2011 rebé el premi Vicent Silvestre de Literatura Infantil dins dels Premis Ciutat d'Alzira. 